\title{
RIGLYNE VIR KULTUURKONGRUENTE GESONDHEIDSVOORLIGTING
}

\author{
Mev. Sonya Beukes \\ M.Cur, Dosent, \\ Departement Verpleegkunde \\ RAU
}

\author{
Prof. AGW Nolte \\ D. Litte et Phil., Professor \\ Departement Verpleegkunde \\ RAU
}

\author{
Dr. E Gross \\ D. Cur \\ RAU
}

\section{OPSOMMING}

Gesondheidsvoorligting is ' $n$ belangrike komponent van gesondheidsbevordering wat gemoeid is met die gesondheidstatus van individue en die gemeenskap. Gesondheidsvoorligting vind daagliks plaas en word deur die verpleegkundige en pasiënt beplan ten einde hom/haar instaat te stel om vrywillig ingeligte gesondheidskeuses uit te oefen op grond van sy/haar eie keuses. Indien die verpleegkundige die pasiënt voorsien met inligting en kennis ten opsigte van gesondheid-en siektegedrag en dit stem nie ooreen met sy/haar kulturele agtergrond nie, sal die verpleegkundige nie daarin slaag om die pasiënt te bemagtig om ingeligte keuses te maak nie, aangesien die inligting nie kultuurkongruent is nie.

Ten einde kultuurkongruente gesondheidsvoorligting te gee moet daar spesifieke aandag aan die beraming van die pasiënt se gekommunikeerde behoeftes gegee word. Beide die verpleegkundige en die pasiënt betree die voorligtingsaksie vanuit hul eie kulturele konteks. Die verpleegkundige se sentrale fokus moet die kulturele agtergrond van die pasiënt wees. Die doel van hierdie studie is om te bepaal tot watter mate gesondheidsvoorligting wat deur finale jaar B. Cur studente op die Phelophepa trein gegee word, kultuurkongruent is. Gesondheidsvoorligtingaksies is geëvalueer ten opsigte van kultuurkongruensie en na aanleiding van die bevinding is riglyne vir kultuurkongruente gesondheidsvoorligting beskryf.

Vir die doeleindes van hierdie studie is daar gebruik gemaak van 'n verkennende, beskrywende en kontekstuele ontwerp. Gesondheidsvoorligting is verken deur video-opnames en geëvalueer aan die hand van naïewe sketse deur kundige evalueerders. Bevindinge is met die literatuur gekontroleer en aan die hand hiervan is riglyne vir kultuurkongruente gesondheidsvoorligting in gemeenskapsverpleegkunde beskryf.

Die algemene bevindinge dui daarop dat gesondheidsvoorligting nie kultuurkongruent is nie. Die drie hoofkategorieë wat geïdentifiseer is, is ' $n$ leemte in kulturele agtergrondsberaming, waardeverheldering en oneffektiewe kultuurkongruente kommunikasie. Die drie hoofkategorieë word ondersteun deur die drie beginsels vir kultuurkongrnensie wat deur Chrisman beskryf is naamlik kennis, wedersydse respek en onderhandeling. Riglyne vir kultuurkongruente gesondheidsvoorligting is aan die hand van 'n modelgeval beskryf.

\section{SUMMARY}

Health Education is an important component of health promotion, which is concerned, with the health status of both the individual and the community. Health education takes place daily and is planned by the nurse and the patient in order to enable the latter to willingly make independent informed decisions about health and to practice those of his/her own choice. If the nurse provides the patient with information and knowledge concerning health and illness management and this information is not compatible with his/her cultural background, the nurse will not succeed in enabling the patient to make informed choices, as the information is not congruent with the prevailing cultural milieu.

In order to provide culture-congruent health information, specific attention must be given to the planning of the patient's communicated needs. Both the nurse and the patient approach the education process from their own cultural context. The nurse's central focus must be the cultural context of the patient.

The aim of this study is to determine to what extent health education given by final year BCur students on the Phelophepa train is culture-congruent. Health education sessions were evaluated. Health education is evaluated for culture congruence and as a result of the findings, guidelines for culture congnient health education are described. For the purposes of this study, use was made of a exploratory, descriptive and contextual design. Health education was explored on videotapes and evaluated by means of naive sketches by expert evaluators. These results were compared with the literature and as a result of this, guidelines for culturecongruent health education in community nursing were developed.

The general findings indicate that health education is not culture-congruent. The three main categories that were identified are: $a$ lack in cultural background assessment, value clarification and ineffective culture-congruent communication. These three main categories are supported by the three principles for culture-congruent care described by Chrisman, namely knowledge, mutual respect and negotiation Guidelines for cultural congruent health education have been illustrated by means of a modelcase. 


\section{AGTERGROND TOT DIE STUDIE}

Deur Gesondheidsvoorligting word gepoog om die gesondheid van individue en gemeenskappe te verbeter. Gesondheidsvoorligtingaksies is beplande geleenthede waar individue kennis kan opdoen oor gesondheid, hulle gesondheidsgedrag vrywillig verander en die kwaliteit van hul lewe kan verbeter. Die gesondheidsvoorligtingaksies sluit nie net die voorsiening van inligting in nie, maar eksploreer ook waardes en houdinge.

Suid Afrika het 'n heterogene bevolking met elf amptelike tale en diverse etniese kulture. Ten spyte van die westerse invloed wat deur die blanke bevolkingsgroep uitgeoefen is het elke bevolkingsgroep in Suid Afrika apart ontwikkel en in isolasie van mekaar geleef; gesondheidsvoorligting is ook afsonderlik gedoen (Leininger, 1995:594). Geïntegreede dienslewering het in 1992 in werking getree gebaseer op 'n Primêre Gesondheidsorg benadering. Met die verkiesing in April 1994, het konstitusionele veranderinge in Suid Afrika plaasgevind. Die verpleegperspektief moet dus verskuif van 'n geisoleerde beskouing (enkele kultuur) na 'n multikulturele beskouing. Veral in die landelike areas is daar mense van verskillende kulture en verpleging hou nie altyd tred met veranderinge nie.

\section{Probleemstelling}

Die Phelophepa gesondheidsdiens het in Januarie 1994 aanvang geneem as Primêre gesondheidsorgdiens. Finalejaar voorgraadse studente en enkele na-basiese studente verrig 'n gedeelte van hulle gemeenskapsverpleegkunde praktika op die trein waar hulle verantwoordelik is vir gesondheidsvoorligting wat grootliks onafhanklik van toesighouding gegee word. Hoewel studente onderrig word in die vaardigheid om waardeverheldering te doen, ontstaan die vraag tog of die gesondheidsvoorligting wat deur die studente aan pasiënte in die landelike gebiede gegee word, kultuurkongruent is.

\section{Die doel van die studie}

Die doel van hierdie studie is om te bepaal tot watter mate gesondheidsvoorligting wat deur finale jaar B.Cur studente op die Phelophepa trein gegee word, kultuurkongruent is en aan die hand daarvan riglyne vir kultuurkongruente gesonheidsvoorligting te beskryf.

\section{NAVORSINGSMETODIEK}

\section{Navorsingsontwerp}

'n Verkennende, beskrywende en kontekstuele ontwerp is vir die doeleindes van hierdie studie gebruik (Mouton \& Marais, 1992:48). Gesondheidsvoorligting wat deur finalejaar verpleegkundiges op die Phelophepa trein gegee is, is verken om te bepaal of die gesondheidsvoorligting aangebied word met inagneming van die pasiënte se kultuur. $\mathrm{Na}$ aanleiding van die bevindinge van die navorsing, is riglyne vir kultuurkongruente gesondheidsvoorligting vir gemeenskapsverpleegkundiges beskryf.

\section{Navorsingsmetode}

Die studie verloop in twee fases.

Tabel 1: Skematiese voorstelling van die verloop van die studie

\begin{tabular}{|c|c|}
\hline FASE I & VGRKGNNTNGANGESONDHATSYOORUGTING \\
\hline l & DATA-INSAMELING \\
\hline Stap 1 & Maak van video-opnames oor voorligtingaksies \\
\hline Stap 2 & Evaluering van video's an die hand van naïewe sketse deur kundiges \\
\hline Stap 3 & Loodsstudie \\
\hline 2 & DATA-ANALISE \\
\hline Stap 1 & Kodering van nailewe sketse \\
\hline Stap 2 & Verantwoording van individuele bevindinge met individuele kundiges \\
\hline Stap 3 & Verfyning van data \\
\hline Stap 4 & Verantwoording van finale bevindinge met alle kundiges \\
\hline Stap 5 & Literatuurkontrole \\
\hline FASE 2 & 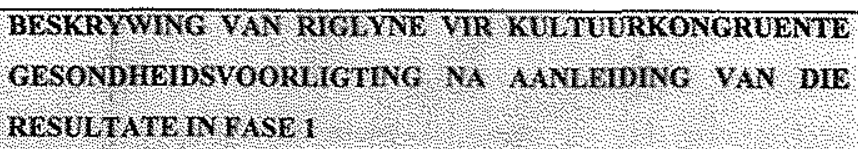 \\
\hline
\end{tabular}

FASE 1: VERKENNING VAN GESONDHEIDSVOORLIGTING

\section{Data-insameling}

Twee stappe is gevolg in die data-insameling, naamlik:

\section{Stap 1: Die maak van video opnames \\ - Populasie en steekproef}

Die populasie vir die studie bestaan uit ses-en-dertig finalejaar verpleegkundiges wat Primêre Gesondheidsorg oor 'n periode van 4 weke op die Phelophepa trein lewer. Die populasie wat gesonheidsvoorligting ontvang bestaan uit pasiënte wat Phelophepa trein besoek.

\section{- Steekproef}

'n Eenvoudige ewekansige steekproef van een uit die vier weke is getrek deur aan die weke nommers te allokeer. Nege studentverpleegkundiges wat in 'n betrokke week by een van die besoekpunte in KwaZulu Natal, Primêre Gesondheidsorgdiens op die Phelophepa trein lewer het deel geneem aan die navorsing. Die pasiënte wat by die navorsing ingesluit word, is toevallig ingesluit uit al die pasiënte wat die trein besoek. Nege video-opnames van verskillende gesondheidsvoorligtingaksies is oor een dag opgeneem (Burns \& Grove, 1993:245; Woods \& Catanzaro 1988:107). 
- Tegniese aspekte met betrekking tot die maak van video opnames

Om die kwaliteit van goeie video-opnames te verseker is daar van 'n professionele fotograaf gebruik gemaak. Aangesien die toerusting wat deur die fotograaf gebruik van so aard is dat die kwaliteit van die opnames dadelik bepaal kan word, is elke video opname as 'n proefopname beskou (Heacock, Souder \& Chastian, 1996:334-339; Roberts, Srour \& Winkelman, $1996: 336-338)$

\section{Stap 2: Nä̈ewe sketse na aanleiding van die voorligtingaksie video's}

Vir die evaluasie van video-opnames is gebruik gemaak van 'n doelbewuste seleksie van kundige evalueerders naamlik gemeenskapsverpleegkundiges, 'n antropoloog, transkulturele kundiges en gemeenskapsverteenwoordigers. Die geïdentifiseerde kundige evalueerders is gevra om die video-opnames van gesondheidsvoorligtingaksies met behulp van naïewe sketse vir kultuurkongruensie te evalueer (Burns \& Grove, 1993:246; Woods \& Catanzaro, 1988:80).

\section{Data Analise}

Vyf stappe in die analise en verantwoording van die data is gevolg.

\section{Stap 1: Kodering van naïewe sketse}

$\mathrm{Na}$ aanleiding van Tesch (Creswell, 1994:153-160), is die naïewe sketse volgens die agt stappe geanaliseer en gekodeer. Onderwerpe wat verwant is aan mekaar is saam gegroepeer.

\section{Stap 2: Verantwoording van individuele} bevindinge met individuele kundige evalueerders

Ten einde vertrouenswaardigheid te verhoog is die individueel gekodeerde data, saam met die oorspronklike naïewe sketse, getranskribeerde verloop van video's en video-opnames na elke kundige evalueerder terugverwys ter bevestiging dat die data verteenwoordigend is van die kundige evalueerder se eie veelvuldige realiteite (Lincoln \& Guba 1985:290300 ).

\section{Stap 3: Verfyning van data}

Nadat die data terug ontvang is van die individuele kundige evaluereerders is dit verfyn en in gesamentlike samevatting van al die kundige evalueerders is opgestel (Creswell, 1994:153-160).

\section{Stap 4: Verantwoording van finale bevindinge met alle kundige evalueerders}

Die gesamentlike opsomming van die gekodeerde data is terugverwys na elke kundige evalueerder ter bevestiging van die kategorieë wat geïdentifiseer is. Die kundiges het bevestig dat dit die waarheid is.

\section{Stap 5: Literatuurkontrole}

Die kategorieë oor multikulturele aspekte en gesondheidsvoorligting is met die literatuur gekontroleer. In die literatuurkontrole wat oor gesondheidsvoorligting en multikulturaliteit gedoen is, is vertrouenswaardigheid van die studie verseker deur gebruik te maak van 'n verskeidenheid databronne (Denzin \& Lincoln, 1994:153-160).

\section{- Loodstudie}

Een kundige evalueerder is gekontak en gevra om die nege video-opnames te evalueer vir kultuurkongruensie met behulp van naïewe sketse. Die doel hiervan was om die metode te suiwer (Burns \& Grove, 1993:48).

FASE 2: BESKRYWING VAN RIGLYNE VIR KONGRUENTE GESONDHEIDS VOORLIGTING NA AANLEIDING VAN DIE RESULTATE IN FASE 1

Aan die hand van die resultate verkry in Fase 1 en literatuurkontrole is riglyne vir kultuurkongruente gesondheidsvoorligting vir die gebruik in die gemeenskapsverpleegkundige praktyk beskryf.

\section{VERTROUENSWAARDIGHEID VAN DIE STUDIE}

Vertrouenswaardigheid van die studie is verseker deur die gebruik van Lincoln en Guba (1985:290-300) se model wat kriteria stel vir vertrouenswaardigheid, naamlik geloofwaardigheid, oordraagbaarheid, vertroubaarheid en bevestigbaarheid.

\section{BEVINDINGE}

\section{Algemene bevinding}

Gesondheidsvoorligting is nie kultuurkongruent nie as gevolg aan ' $n$ leemte in kennis, onvoldoende watrdeverheldering en onvoldoende kommunikasie.

Vanuit die bevinding van die studie kan tot die gevolgtrekking gekom word dat gesondheidsvoorligting aan pasiënte gegee word sonder om die kulturele agtergrond van die pasiënte in ag te neem tydens voorligtingsaksies. Volgens Chrisman (1991:36) sal kultuurkongruente gesondheidsvoorligting nie realiseer as die verpleegkundige nie die nodige agtergrondskennis verkry nie. Hierdie kennis is die inligting wat die verpleegkundige verkry oor die pasiënt, sy/haar familie, die gemeenskap en die gedrag wat hulle binne hul gegewe kultuur openbaar. Die verpleegkundige benodig ook kennis oor die pasiënt se waardes en oortuiginge van siekte en gesondheid, wat diep gewortel is in kultuur. Wanneer die verpleegkundige nie oor die nodige kulturele agtergrondskennis beskik nie, kan hy/sy nie die nodige 
Tabel 2: Tabulering van Vertrouenswaardigheid

\begin{tabular}{|c|c|c|}
\hline XKGF I & \multicolumn{2}{|c|}{ 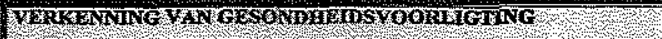 } \\
\hline $\begin{array}{l}\text { A. DATA INSAME- } \\
\text { LNG } \\
\text { STAP I }\end{array}$ & $\begin{array}{l}\text { AKSTE } \\
\text { Maak van video opnames } \\
\text { - Opnames van video ses- } \\
\text { sies }\end{array}$ & 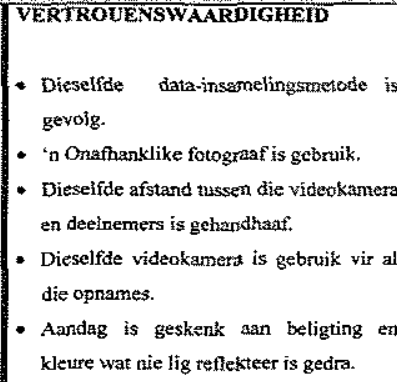 \\
\hline$\overline{\text { STAP2 }}$ & $\begin{array}{l}\text { Naiswe sketse na aanleiding } \\
\text { yan gesondheidsvoorlig- } \\
\text { tingaksies. }\end{array}$ & 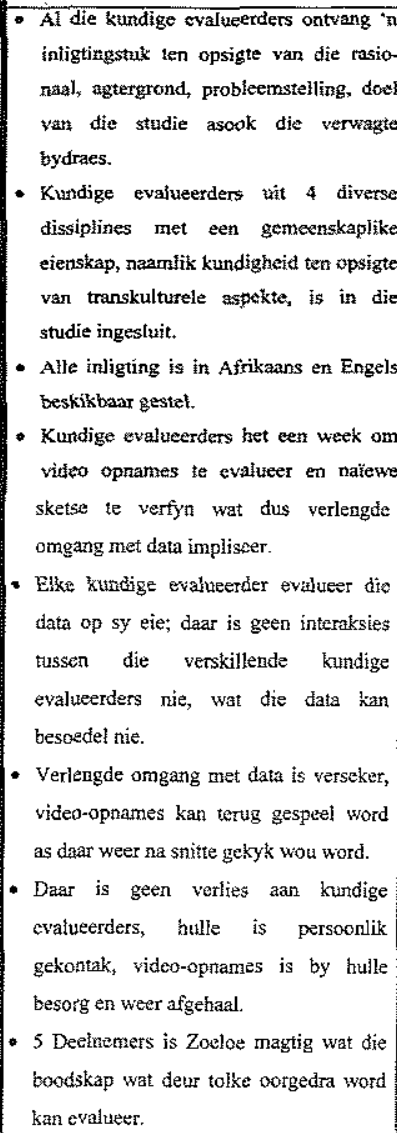 \\
\hline STAP I: & $\begin{array}{l}\text { Kodering van individuele } \\
\text { naïewe sketse }\end{array}$ & $\begin{array}{l}\text { Flke naiewe skets word volgens Tesch se } \\
\text { agt stappe gekodeer deur die navorser } \\
\text { self. }\end{array}$ \\
\hline S'TAP 2: & $\begin{array}{l}\text { Veriftèning yan kundige } \\
\text { evalueerders ter bevestiging } \\
\text { yan hul veelvuldige } \\
\text { realiteite }\end{array}$ & $\begin{array}{l}\text { - Deur die gebrik yan lidkontrole is } \\
\text { feitlike foute gekortigeer, foutiewe } \\
\text { interpretasies en persepsies uitgektaar } \\
\text { met kundige evalueerders. } \\
\text { - Addisionele iningting is beskikbaar gestel } \\
\text { - Rekord van die kundige evalueerders se } \\
\text { bevestiging van korrektheid van data is } \\
\text { vorkis. }\end{array}$ \\
\hline$S T+P^{3}$ & Vorlyning vaun data & 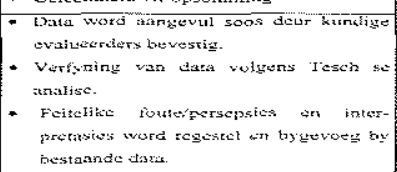 \\
\hline 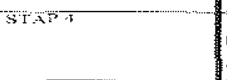 & 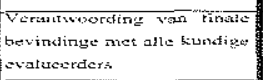 & 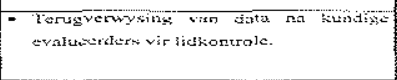 \\
\hline 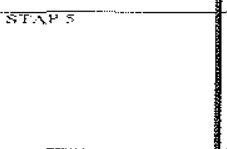 & 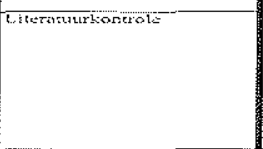 & 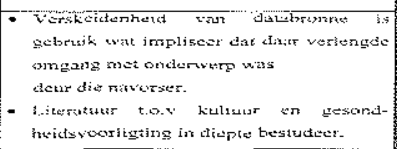 \\
\hline & & $\mathrm{NE} \times \mathrm{NA}$ \\
\hline
\end{tabular}

\begin{tabular}{|c|c|c|}
\hline & & $\begin{array}{l}\text { verkry. } \\
\text { - Geleentheid vir opsomming }\end{array}$ \\
\hline STAP 3 & Verfyning van data & $\begin{array}{l}\text { - Data word aangevul soos deur kundige } \\
\text { evalueerders bevestig. } \\
\text { - Verfyning van data volgens Tesch se } \\
\text { analise. } \\
\text { - Feitelike foute/persepsies en inter- } \\
\text { pretasies word regestel en bygevoeg by } \\
\text { bestaande data. }\end{array}$ \\
\hline STAP 4 & $\begin{array}{l}\text { Verantwoording van finale } \\
\text { bevindinge met alle kundige } \\
\text { evalueerders }\end{array}$ & $\begin{array}{l}\text { - Terugverwysing van data na kundige } \\
\text { evalueerders vir lidkontrole. }\end{array}$ \\
\hline STAPS & Literatururkontrofe & $\begin{array}{l}\text { Verskeidenheid van donabronne is } \\
\text { gebruilk wat impliseer dat daar verlengde } \\
\text { omgang met onderwerp was } \\
\text { deur die navorser. } \\
\text { - Literatuur to.v kultuur en gesond- } \\
\text { heidsvoortigting in diepte bestudeer. }\end{array}$ \\
\hline FASE 2 & $\begin{array}{l}\text { BESKRYWING VAN RI } \\
\text { RESULTATE IN FASE } \mathrm{i}\end{array}$ & GLYNE NA AANLEIDING VAN DIE \\
\hline
\end{tabular}

respek vir die pasiënt se kultuur en omstandighede openbaar nie. Die respek wat die verpleegkundige vir die pasiënt se kulturele waardes en oortuiginge toon fasiliteer samewerking en respek tussen die verpleegkundige en pasiënt. Dit impliseer dat die verpleegkundige voorligtingsaksies met 'n oop, nieveroordelende houding betree en dat die pasiënt se gekommunikeerde behoeftes aan gesondheid sentraal staan tot die verhouding. Wanneer die verpleegkundige begrip toon vir die pasiënt se gedrag binne die konteks van die pasiënt se kultuur vind onderhandeling tussen die verpleegkundige en pasiënt plaas. Die onderhandeling het ten doel om die nodige inligting van die pasiënt te verkry asook om leemtes in die pasiënt se kennisinhoud aan te vul sodat die pasiënt die inligting kan gebruik om haar/sy eie gesondheid te optimaliseer. As daar oop kommunikasiekanale gevestig is tussen die verpleegkundige en die pasiënt voel albei dat hulle kulturele waardes en oortuiginge wedersyds hoog aangeskryf word. Die onderhandelingsproses tussen die verpleegkundige en pasiënt het ten doel om die pasiënt se gesondheid te optimaliseer (Chrisman, $1991: 36,37,45,46)$.

Die resultate soos wat weergegee word in tabel 3 is die finale resultate soos goedgekeur deur die kundige evalueerders nadat hulle verantwoord het dat die kodering juis is.

Uit tabel 3 is dit duidelik dat die hoof- en subkategorieë wat geïdentifiseer is, almal verband met mekaar hou. Terwille van die wetenskaplike proses is die bevindinge soos verkry uit die naïewe sketse streng volgens die kategorieë met die literatuur gekontrolleer. In die verskillende kategorieë is daar van kruisverwysings gebruik gemaak omdat die bevindinge met mekaar verweef is en nie los van mekaar staan nie. 
Tabel 3: Kategorieë geïdentifiseer na aanleiding van nailewe sketse

\begin{tabular}{|c|c|}
\hline ALGEMENE BEVINDNNG & GESONDHEDSVOORLIGTING IS NIE KULTUURKONGRUENT NIE \\
\hline HOOFKATEGORII & ONVOLDOENDE KULTURELE AGTERGRONDSKENNIS \\
\hline SUBKATEGORIE 1 & 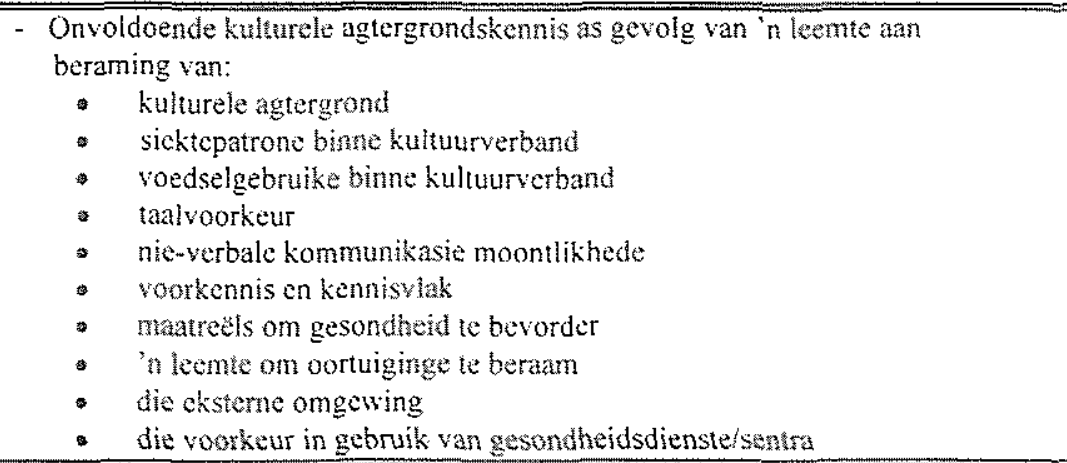 \\
\hline HOOFKATEGORT 2 & ONVOLDOENDE W $\times$ NRDEVERTEUDERING \\
\hline SUBKATEGORIE 2 & $\begin{array}{l}\text { Onvoldoende waardeverhelderingsaksie as gevolg van veroordelende houding } \\
\text { van die verpleegkundige } \\
\text { lecmte aan motivering as gevolg van onvoldoende waardeverheldering }\end{array}$ \\
\hline HOOFK HILCORIE 3 & ONVOLDOENDE KULTUURKONGRUENTE KOMMUNIK ASIL \\
\hline SUBKATEGORIE 3 & 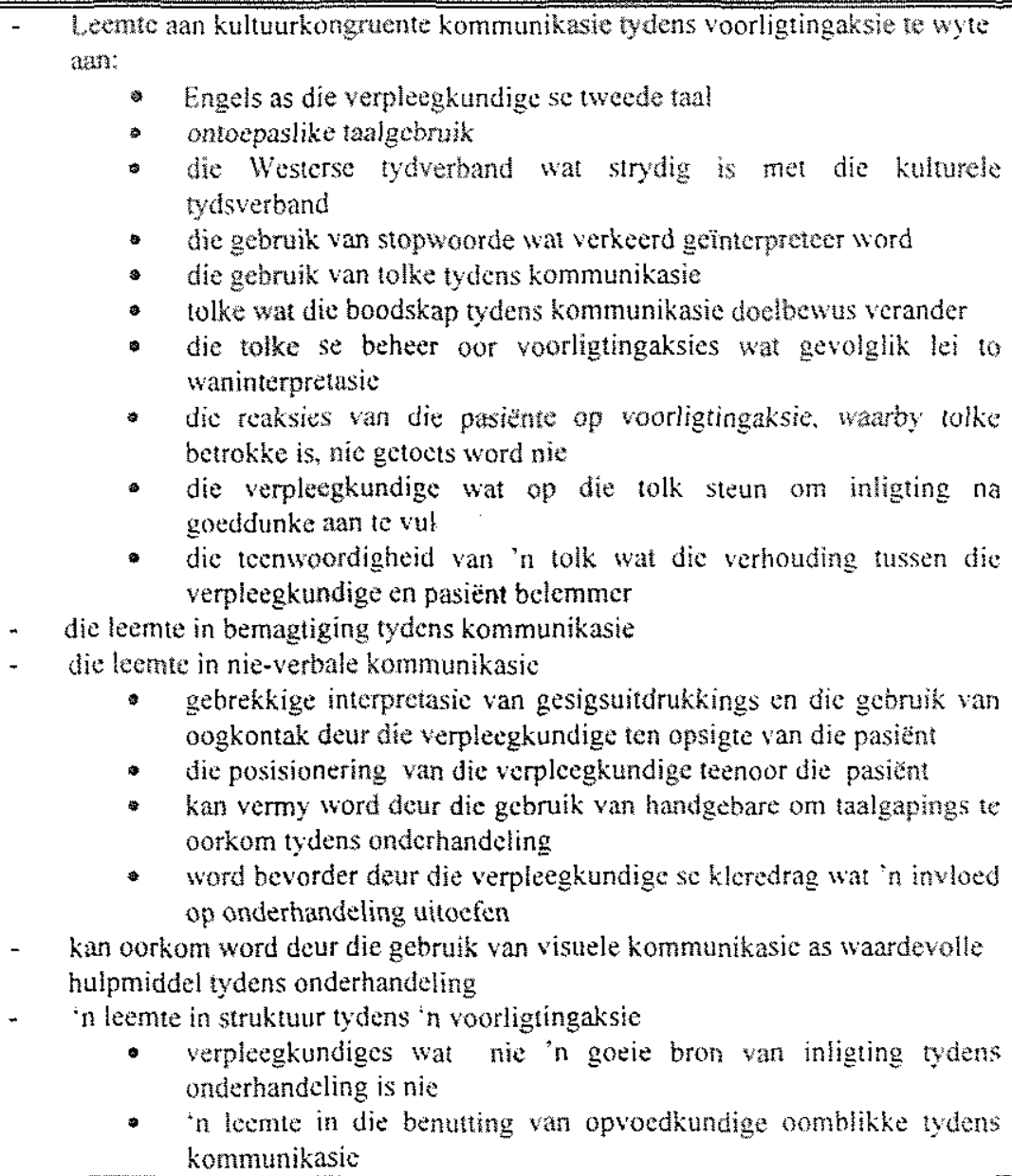 \\
\hline
\end{tabular}

\section{HOOFKATEGORIE 1: ONVOLDOENDE KULTURELE AGTERGRONDSKENNIS}

Voordat enige gesondheidsvoorligtingsaksie deur 'n verpleegkundige betree word, is dit nodig dat die verpleegkundige 'n deeglike en noukeurige beraming van die pasiënt se kulturele agtergrond en gesondheidsprobleme maak ten einde te verseker dat die voorligting wat aangebied word kultuurkongruent is. Die subkategorieë soos gelys in bostaande tabel is geïdentifiseer na aanleiding van onvoldoende agtergrondskennis oor kultuur.
Die hoof en subkatogorie 'Onvoldoende agtergrondskennis' stem ooreen met die beginsel van kennis wat deur Chrisman beskryf is. Chrisman (1991:36) beskryf kennis binne kultuurverband as die inligting wat 'n verpleegkundige verkry ten opsigte van die pasiënt, die familie, die gemeenskap en hul gedrag wat hulle openbaar tydens gesondheid en siekte. Dit behels die faktore wat 'n rol speel in die benutting van gesondheidsdienste of sentra, kennis waaroor die pasiënt beskik ten opsigte van gesondheid en siekte. Die verpleegkundige moet vasstel hoe die pasiënt dink, wat haar/sy oortuiginge is en hoe dit haar/sy gedrag 
beïnvloed. Die verpleegkundige verkry die kennis ten opsigte van die pasiënt vanuit die volgende bronne:

- Die verpleegkundige bou oor die jare kennis op oor die pasiënt se oortuiginge en gedragwyses.

- Die pasiënt en die familie is 'n groot bron van inligting oor hulle hanteringsmeganismes tydens siekte en ook hul siekte geskiedenis.

- Literatuur, boeke artikels en pamflette.

Hierdie kulturele agtergrondskennis sal die verpleegkundige rig sodat hy/sy kultuurkongruente gesondheidsvoorligting kan gee.

\section{HOOFKATEGORIE 2: ONVOLDOENDE WAARDEVERHELDERING}

In 'n pluralistiese samelewing moet verpleegkundiges voorbereid wees om met alle pasiënte te werk ongeag hulle kulturele agtergrond, sodat kultuurkongruente sorg aan elke pasiënt gegee kan word. Om kultuurkongruente sorg te gee moet verpleegkundiges begrip toon vir verskillende faktore wat individuele gesondheid- en siektegedrag beïnvloed (Giger \& Davidhizar, 1991:n).

Met behulp van waardeverhelderingsstrategieë verkry die verpleegkundige die nodige kennis ten opsigte van die invloed wat kultuur op gesondheid en siekte het, asook die voorgeskrewe praktyke om gesondheid te bevorder en siekte te voorkom (Giger \& Davidhizar, 1991:n). Hy/sy het egter ook kennis van die pasiënt se waardes en oortuiginge nodig om hom/haar in staat te stel om die nodige respek te toon vir die pasiënt se waardes. Hy/sy beskou die pasiënt as 'n kundige gespreksgenoot en kenner van sy/haar eie gesondheid (Gross, 1994:175)

Waarderverheldering binne die konteks van hierdie studie ondersteun die begrip van wedersydse respek wat deur Chrisman (1991:36, 37) beskryf is. Wedersydse respek is interafhanklik van die agtergrondkennis wat die grondslag is vir samewerking en die daarstelling van 'n vertrouensverhouding tussen die verpleegkundige en die pasiënt. Die verpleegkundige gebruik die kennis wat hy/sy tydens die beramingsfase bekom, en beskou die gedrag en optrede van die pasiënt binne die konteks van sy/haar kultuur. Wanneer daar geen wedersydse respek tussen die verpleegkundige en pasiënt is nie, kan 'n vertrouensverhouding nie gevestig word nie. Dit is 'n hindernis tydens bemagtiging en onderhandeling met die pasiënt.

\section{HOOFKATEGORIE 3: ONVOLDOENDE KULTUURKONGRUENTE KOMMUNIKASIE}

Kommunikasie en kultuur is verwant. Deur kommunikasie word kultuur van een generasie na die volgende oorgedra. Kommunikasie met pasiënte van verskillende etniese en kulturele agtergrond is krities in die voorsiening van kultuurkongruente gesondheidsvoorligting omdat daar baie variasie in beide verbale en nie verbale kommunikasie is (Kozier, et al. 1997:362).

Die bevindinge in hierdie kategorie, (kyk tabel 3) toon dat daar 'n leemte aan kultuurkongruente kommunikasie is. Aspekte geïdentifiseer as leemtes omsluit verbale, nie-verbale en geskrewe kommunikasie, asook sekere aspekte tydens die voorligtingsaksie wat dui op ontoereikende beplanning, opvoedkundige oomblikke wat nie benut word nie en deelname van pasiënte aan voorligtingaksies wat nie gefasiliteer is nie. Die kategorie ondersteun die beginsel van onderhandeling wat deur Chrisman beskryf word. Volgens Chrisman (1991:36, 37) is onderhandeling aksie georiënteerd. Die verpleegkundige moet die pasiënt se gedrag binne die konteks van sy/haar kultuur verstaan. As oop kommunikasie kanale tussen die pasiënt en die verpleegkundige gevestig is, sal albei partye voel dat hul waardes en oortuiginge hoog aangeskyf word. Die hoofdoel van onderhandeling tussen die pasiënt en verpleegkundige is om saam te werk, en sodoende die pasiënt se gesondheid te optimaliseer (Chrisman, 1991:36, 37). Volgens die onderhandelingsproses luister die verpleegkundige na die pasiënt en gee, voorligting nadat hy/sy die pasiënt se bestaande kennisvlak beraam het. Dit beteken dat kennis wat die pasiënt reeds het versterk word, en dit wat die pasiënt nie weet nie deur die verpleegkundige op so 'n wyse oorgedra word dat dit in die pasiënt se behoeftes voorsien (Chrisman, 1991:36-37, 45-46). Die pasiënt se behoeftes moet onder alle omstandighede sentraal staan. Die verpleegkundige moet sy/haar eie biomediese perspektief verstaan en ook vertroue daarin hê. Hy/sy moet egter ook die pasiënt ondersteun en sy/haar sienswyse op 'n duidelik manier aan die pasiënt oordra deur die implikasies van sy/haar voorstelle aan die pasiënt te verduidelik.

\section{FASE 2: RIGLYNE VIR KULTUUR- KONGRUENTE GESONDHEIDS- VOORLIGTING}

Riglyne vir kultuurkongruente gesondheidsvoorligting is volgens die verpleegproses en aan die hand van 'n modelgeval beskryf.

\section{Die modelgeval}

Mev. Molotto is 'n vyf-en-vyftigjarige dame wat in 'n landelike, informele huisvesting in Kwa-Zulu Natal by haar dogter en 3 kleinkinders inwoon. Mev. Molotto se enigste bron van inkomste is R300 wat deur haar man, wat in Johannesburg by 'n oliefabriek werk, aan haar gestuur word en sy vul dit aan met ongeveer R300 uit verkope van groente wat sy in haar tuin plant. Mev Molotto is net Zoeloe magtig en woon ' $n$ kliniek by. Sy kla van hoofpyn, duiseligheid en dispneę. Met die eerste blik is dit duidelik dat sy oorgewig is en haar 
hande en voete lyk geswel.

\section{Beramingsfase}

Die verpleegkundige moet die volgende data insamel ten einde te verseker dat hy/sy al die nodige inligting bekom om die gesondheidsvoorligtingsessie te fokus.

\section{Kulturele Agtergrond}

Die volgende aspekte van Mev. Molotto se kulturele agtergrond moet beraam word:

- Mev Molotto se kulturele affiliasie en ook of sy met 'n spesifieke kultuurgroep in haar onmiddellike omgewing identifiseer.

- M ev. Molotto se siekte en gesondheidsoortuiginge, die rol van religieuse affiliasie ophaar siekte en gesondheidsoortuiginge en die rol wat di e $\mathrm{si}$ e kte e n gesondheidsoortuiginge speel in die benutting van gesondheidsdienste hetsy tradisionele genesers of die biomediese praktyke. Dit kan gedoen word deurdat die verpleegkundige van Kleinman (in Chrisman, 1991:46) se verduidelikingsmodel gebruik maak tydens die onderhoudvoering:

- Wat noem jy jou siekte?

- Wanneer het dit begin?

- Wat dink jy het die siekte veroorsaak?

- Hoe werk jou siekte?

- Hoe erg is jou siekte en hoe lank duur dit al?

- Watter behandeling moet jy nou kry?

- Wat vrees jy die meeste van jou siekte?

- Die invloed wat kulturele agtergrond op die verbruik en gebruik van voedsel het, met inagneming van die fisiese probleme wat ' $n$ invloed op voedselpraktyke het.

- Die $t a a l$ wat Mev. Molotto praat, en tot watter mate sy die verbaal en geskrewe taal magtig is, beraam.

- Die mate waartoe Mev. Molotto Engels magtig is en wat haar taalvoorkeur vir die voorligtingaksie is.

- Mev. Molotto se gevoel jeens die gebruik van 'n tolk indien sy Engels nie magtig is nie, met inagneming van haar kulturele agtergrond naamlik ouderdom, geslag en kulturele affiliasie van die tolk.

- Die reëls wat gevolg moet word ten opsigte van die aanspreekvorms wat anvaarbaar is binne Mev. Molotto se kultuur.

- Die reëls ten opsigte van die tempo waarteen voorligting gegee moet word, die onderwerp taboes, verduidelikings en vertroulikheid van inligting wat tussen Mev. Molotto en die verpleegkundige uitgeruil word.

- Nie-verbale kommunikasievaardighede naamlik oogkontak, liggaamshouding, posisie, die gebruik van handgebare en nie-verbale aanduidings binne Mev. Molotto se kulturele agtergrond.

\section{Omgewings Beraming}

Hierdie beraming word verdeel in die beraming van die interne en eksterne omgewing:

\section{Interne Omgewing}

Die anatomiese, biologiese prosesse en die liggaamlike behoeftes van Mev. Molotto.

- Mev. Molotto se gesondheidsbehoeftes, met inagneming van die kulturele agtergrond. Die belangrikste aspekte wat hier ingesluit word is:

- Geslag

- Ouderdom

- Variasie in die liggaamsisteme binne verskillende kultuur groepe

- Die voorkoms van siektepatrone onder spesifieke kulturele en etniese groepe

- Huidige gesondheidsbehoefte

\section{Psigologiese Beraming}

Hierdie beraming is ten nouste verweef met die kulturele agtergrond. Aspekte wat deur die verpleegkundige ingesluit moet word is as volg:

- Mev. Molotto se oortuiging wat sy het ten opsigte van siekte en gesondheid.

- Die invloed van Mev. Molotto se waardes, wat sy deur kultuur aangeleer het, op haar gesondheidsbehoeftes, wilskrag en siening van haarself en die tipe gedrag wat sy tydens siekte en gesondheid openbaar.

- Die mate van gesondheidskennis waaroor Mev. Molotto binne haar kulturele agtergrond beskik.

- Mev. Molotto se verwagtinge van die verpleegkundige en hoe sy haar rol in die gesondheidsvoorligtingaksie beskou.

- Die rol wat Mev. Molotto se religieuse affiliasie in haar gesondheid en siekte oortuiginge speel.

\section{Eksterne Omgewing}

Mev. Molotto se fisiese, sosiale en geestelike omgewing waarin sy haar bevind word beraam. Die aspekte wat hier beraam moet word is ook ten nouste verweef met die fisieke en psigologiese beraming.

Aspekte wat hier aandag moet geniet is:

- Omgewingsgeografie

- Siekte agente

- Gesondheidsdienste en sosiale netwerke wat beskikbaar is in Mev. Molotto se omgewing

- Sosio-ekonomiese status, met spesifieke verwysing na inkomste

- Mev Molotto se opvoedkundige vlak. Hierdie opvoedkundige vlak beïnvloed haar kennisvlak en taalvaardigheid.

- Beraming van die sosiale netwerke binne die gesin en familie en ook die betekenisvolle mense binne die groter gemeenskap. Dit sluit ook ond ers te uningsgroepe binne die gemeenskap in.

- Beroepsuitlewing van Mev. Molotto.

- Die tipe behuising is ten nouste verweef met die kulturele agtergrond, die fisiese omgewing en die finansiële vermoë van Mev. Molotto.

- Die inkomste groep waaronder Mev. Molotto ressorteer. Dit is bepalend van die tipe behuising, die voedingstaat en die vermoë om gesondheidsorg te bekom. 


\section{Beplanningsfase}

Dit is noodsaaklik dat die verpleegkundige eers selfondersoek instel na sy/haar eie waardegesitueerdheid voordat hy/sy die gesondheidsvoorligtingaksie betree. Die beplanningsfase se sukses word bepaal deur 'n gedetailleerde beramingsfase. Tydens die beplanningsfase is die verduideliking van die doelstellings en doelwitte sentraal asook die voorbereiding van die onderigmedia. Die verpleegkundige neem al die inligting wat hy/sy bekom het tydens beraming en orden die verloop van die voorligtingaksie. Die volgende aspekte moet tydens die beplanningsfase aandag geniet:

\section{Taal}

Binne die kulturele verband is taal reeds 'n probleem, wat verder bemoeilik word as die verpleegkundige in Engels as sy/haar tweede taal voorligting aan pasiënte gee. Die boodskap word nie duidelik en op die man af deur die verpleegkundige oorgedra aan die pasiënt nie, wat die inhoudelike verder kan kleur en die inligting vir die pasiënt moeilik verstaanbaar maak.

- Om die probleem te oorbrug moet die verpleegkundige poog om waar moontlike sekere woorde wat algemeen gebruik word, soos byvoorbeeld "hypertension" in die pasiënt se taal aan te leer.

- Daar word voorgestel dat Chrisman (1991:46) se vrae deur die verpleegkundige in die taal van die pasiënt aangeleer word, aangesien dit ook die kommunikasie hindernisse oorbrug.

- Die verpleegkundige moet waar moontlik sy/haar sinne kort en op die man af hou en net die belangrikste inligting oordra.

- Wanneer die verpleegkundige kommunikeer moet die inhoudelike logies en sinvol georden word en nuwe kennis moet op reeds bestaande kennis gebou word.

- Tydens ' $n$ gesondheidsvoorligtingaksie moet van die maklike na die moeilike en van die konkrete na die abstrakte beweeg word.

- Die verpleegkundige moet waak teen die gebruik van mannerismes. Dit kan hinderlik wees as dit nie kongruent is met die pasiënt se kulturele agtergrond nie.

- Die verpleegkundige moet gebruik maak van nieverbale kommunikasie byvoorbeeld oogkontak, handgebare en posisionering tydens gesondheidsvoorligting. Dit kan die verpleegkundige help om die boodskap wat hy/sy oordra te versterk, solank dit kongruent is met die kulturele agtergrond.

- Wanneer daar oor kultuurgrense heen gewerk word en die verpleegkundige nie die taal van pasiënte magtig is nie moet die gebruik van mediese terminologie vermy word want dit skrik pasiënte af.

\section{Die gebruik van tolke}

Daar word dikwels van tolke gebruik gemaak om boodskappe aan pasiënte te vertaal. Aangesien dit beduidend is dat die tolke boodskappe vertolk volgens hul eie goeddunke en dit volgens hul eie oortuiginge kleur, moet aandag aan spesifieke aspekte by die gebruik van tolke gegee word. Tolke moet aan die volgende keuring standaarde onderwerp word:

- Pasiënte moet toestem tot die gebruik van tolke in voorligtingaksies.

- Tolke moet waar moontlik opgelei wees.

- Tolke moet bekend wees met die kulturele agtergrond van die pasiënte en waar moontlik tot dieselfde kultuurgroep behoort.

- Tolke moet geëvalueer word tot welke mate hulle Engels as ' $n$ tweede taal magtig is, asook dic begrip wat hulle het van die gekommunikeerde boodskap. Hulle moet ' $n$ boodskap vertaal in die pasiënt se taal en dit moet deur 'n kenner van die taal geëvalueer word vir akkuraatheid van die boodskap wat oorgedra is.

- Tolke se rol moet duidelik uitgespel word. Hulle is net daar vir die akkurate vertolking van die boodskap, nie om dit volgens hul eie kulturele raamwerk te kleur nie.

- Tolke moet nie sentraal staan tot die gesondheidsvoorligtingaksie nie. Hulle moet deur die verpleegkundige op die agtergrond geposisioneer word sodat die verhouding wat die verpleegkundige met die pasiënt opbou nie belemmer word nie.

- Die verpleegkundige moet poog dat die boodskap sin vir sin vertolk word. Dit sal die tolk help om op die inhoud van die sin te fokus en sodoende die boodskap so akkuraat moontlik te vertolk.

- Die verpleegkundige moet die tolk vra om aan hom/haar te sê wat die inhoud van die boodskap is wat die tolk aan die pasiënt oorgedra het, sodat hy/sy insae kan kry in die akkuraatheid waarmee die boodskap vertolk is.

- Die verpleegkundige moet ook telkens vir die tolk vra wat die pasiënt se reaksie op die voorligting was. Dit stel hom/haar in staat om te evalueer tot watter mate die gesondheidsvoorligting kongruent is met die pasiënte se kultuur.

- Die verpleegkundige moet ook in die geval waar daar gebruik gemaak word van tolke toenemend fokus op die nie-verbale aanduidings van die pasiënte, wat hom/haar in staat stel om te bepaal of die inligting kultuurkongruent is.

\section{Beplanning van onderrighulpmiddels}

- Die verpleegkundige moet die gebruik van onderrighulpmiddels beplan sodat dit kongruent is met Mev. Molotto se kultuur en haar g e 1 e $t$ t e r d heidsvlak. Indien Mev. Molotto nie kan lees nie, moet daar van prente gebruik gemaak word. Die onderrighulpmiddels moet prakties, en duidelik verstaanbaar wees vir Mev. Molotto.

- Die verpleegkundige moet beplan watter tipe, wanneer en hoe hy/sy die onderrighulpmiddels in die voorligtingaksie gaan gebruik.

- Die gebruik van geskrewe hulpmiddels of enige vorm van media moet die voorligtingaksie aanvul. Die gebruik van die hulpmiddels moet die 
inhoudelike van die voorligtingaksie aanvul. Dit moet nie die inhoudelike vervang of strem nie.

\section{Beplanning van die inhoud van die gesondheids- voorligtingaksie}

- Die verpleegkundige moet sorg dat hy/sy tydens die beplanningsfases die kennis waaroor hy/sy beskik op so 'n wyse voorberei dat dit kongruent is met Mev. Molotto se beraamde kulturele oortuiginge.

- Die kennis wat deur die verpleegkundige oorgedra word tydens die voorligtingaksie moet tred hou met die nuutste wetenskaplike vernuwing maar ook met die hulpbronne waaroor Mev. Molotto binne haar kulturele raamwerk beskik.

\section{Beplanning van die ordening van die gesondheidsvoorligtingaksie}

- Die verpleegkundige moet die gesondheidsvoorligtingaksie orden en inligting in 'n logiese formaat uiteensit wat sal verseker dat Mev. Molotto nie verward sal raak met die inligting wat aan haar oorgedra word nie.

- Doelstellings en doelwitte wat deur die verpleegkundige geformuleer word vir die voorligtingaksie, sal help om struktuur aan die gesondheidsvoorligtingaksie te gee. Dit verseker dat Mev. Molotto die verpleegkundige as 'n kundige beskou en sodoende word bemagtiging van Mev. Molotto gefasiliteer.

\section{Die verpleegkundige se voorkoms tydens gesondheidsvoorligtingaksies}

- Die voorkoms van die verpleegkundige is belangrik. Die verpleegkundige moet beraam watter konnotasie Mev. Molotto heg aan die dra van 'n uniform, byvoorbeeld outoriteit. Indien - dit 'n hindernis gaan wees in die bou van 'n terapeutiese verhouding tussen hom/haar en Mev. Molotto en die bemagtiging van Mev. Molotto gaan kortwiek, is dit nodig dat daar herbesin word oor die dra van ' $n$ uniform tydens voorligtingaksies.

\section{Beplanning van deelname deur die pasiënt aan gesondheidsvoorligtingaksies}

- Interaktiewe kommunikasie fasiliteer bemagtiging. Waar daar voorligting aan individue van ' $\mathrm{n}$ ander kultuur gegee word is dit beter om met hul in gesprek te tree om sodoende inligting van hulle te bekom oor hul idees rondom gesondheidsaspekte. Die verpleegkundige kan in die voorligtingaksies met Mev. Molotto gebruik maak van Chrisman (1991:36-37, 46-47) se strategie van kennis, wedersydse respek en onderhandeling. Hierdie strategie is regdeur die hele proses verweef in die beraming, beplanning, implementering en ook in die evaluering.

- Die verpleegkundige moet aan Mev. Molotto die geleentheid gee om deel te neem deur middel van vrae te vra. In 'n groepsituasie is dit egter nodig dat die verpleegkundige die groep se kulturele agtergrond beraam voordat individue gevra word om deel te neem. In sekere kulture word jong mense nie toegelaat om vrae te antwoord in die teenwoordigheid van ouer mense of bejaardes nie. Waar pasiënte deelneem aan die voorligtingaksies word hulle aandag beter behou en word die inligting makliker deur hulle herroep.

\section{Waardeverheldering van die verpleegkundige}

- Die verpleegkundige moet die voorligtingaksie met 'n oop, tegemoetkomende houding betree. Dit is slegs moontlik waar die verpleegkundige begrip en insig het in sy/haar eie gesondheidsoortuiginge.

- Die verpleegkundige gebruik die inligting wat hy/sy bekom het tydens die beraming van Mev. Molotto se oortuiginge, waardes, ervarings en houding en rig sy/haar eie houding sodat hy/sy oop en aanvaarbaar kan wees.

- Tydens die voorligtingaksie en beramingsfase beskou hy/sy Mev. Molotto as 'n waardevolle bron van inligting en kenner van haar eie gesondheid.

- Deur waardverheldering verseker die verpleegkundige dat hy/sy die gesondheidsvoorligtingaksie betree met 'n houding van oopheid en aanvaarding wat verseker dat die verpleegkundige en Mev. Molotto ' $\mathrm{n}$ terapeutiese verhouding vestig wat daartoe sal lei dat Mev. Molotto sal deelneem aan die voorligtingaksies en ook vrywillig inligting aan die verpleegkundige bekend sal maak.

\section{Implementeringsfase}

Tydens die implementeringsfase word alle aksies wat deur die verpleegkundige beraam en beplan is vir die duur van die gesondheidsvoorligtingaksies geïmplementeer.

\section{Individuele of groepsdeelname aan die voorligtingaksie}

- Die verpleegkundige wat in die beplanning groepsdeelname wil fasiliteer, implementeer die aksies. Hy/sy moet die vrae wat hy/sy wil vra deurvleg in die hele gesondheidsvoorligtingaksie, aangesien mense van verskillende kulturele agtergronde meer leer uit interaktiewe voorligtingaksies.

- Die verpleegkundige kan ook na afloop van 'n voorligtingaksie of deurlopend tydens die aksies vrae aan Mev. Molotto stel om te beraam of sy die inhoudelike van die voorligting verstaan en reg vertolk. Dit is egter nodig om in groepsverband nie direkte vrae aan individue te stel nie aangesien hulle bedreig mag voel en totaal kan onttrek van die aksie, wat teenstrydig is met die konsep van bemagtiging.

- Die verpleegkundige moet erkenning aan Mev. Molotto gee vir haar bydrae tot deelname aan die voorligtingaksies omdat dit haar aanspoor tot verdere deelname aan die gesondheids- 
voorligtingaksies.

\section{Die benutting van opvoedkundige oomblikke}

- Die verpleegkundige moet bedag wees op die opvoedkundige oomblikke wat tydens voorligtingaksies mag opduik om dit optimaal te benut. Hy/sy sal slegs in staat wees om dit sonder skroom te benut as hy/sy goed onderlê is met Mev. Molotto se kulturele agtergrond, met ander woorde die inligting wat hy/sy bekom het uit die beramingsfases asook die teoretiese kennis wat hy/sy internaliseer tydens sy/haar opleiding.

- Die verpleegkundige moet ook gefokus wees op, en bewus wees van opvoedkundige oomblikke wat opduik in die voorligtingaksies. Hy/sy moet dit optimaal benut, omdat dit daartoe kan bydra om vir pasiënte waardevolle inligting te gee.

\section{Die verwysing van pasiënte na gesondheids- dienste}

- Indien die verpleegkundige Mev. Molotto wil verwys na 'n gesondheidsdiens byvoorbeeld 'n kliniek, is dit nodig dat die kliniek opset kongruent is met Mev. Molotto se kulturele oortuiginge, waardes en houding. Dit is nodig dat die verpleegkundige terugverwys na die data wat hy/sy bekom het tydens die beramingsfase om Mev. Molotto toepaslik te verwys.

Dit is noodsaaklik dat die verpleegkundiges wat toenemend aan 'n multikulturele konteks blootgestel word tydens hul opleiding deeglik onderlê word in kultuurkongruente interaksie wat hulle sal bemagtig om elke gesondheidsvoorligtingaksies te hanteer met die nodige teoretiese kennis en praktiese vaardigheid. Ten einde dit te laat realiseer moet daar op die volgende aspekte gefokus word:

\section{Die opleiding van verpleegkundiges}

\section{Waardeverhelderingstrategie $\ddot{e}$}

Verpleegkundiges moet in elke studiejaar die geleentheid kry om hul eie waardes te ontgin. Dit is nodig omdat hy/sy elke jaar blootgestel word aan 'n nuwe inhoudelike komponent van verpleegkunde. $\mathrm{Hy} / \mathrm{sy}$ moet self ondersoek instel na sy/haar eie waardes, houdinge, ervaring, vrese en oortuiginge.

Verpleegkundiges moet 'n gedetailleerde teoretiese begronding kry van die verskillende kultuurgroepe binne die Suid-Afrikaanse konteks. Dit is duidelik dat hulle slegs oorsigtelike inligting kry van die verskillende kultuurgroepe, en nie werklik fundamentele kennis om insig in die kulture se kommunikasie gewoontes te verkry nie.

Formatiewe evaluering na afhandeling van elke module in die kursus is nodig om te verseker dat die verpleegkundige goed onderlê is in die voorligtingsvaardighede, waardeverheldering- strategieë en interpersoonlike kommunikasievaardighede, wat nodig is vir die verplegingspraktyk in 'n multikulturele konteks.

\section{AANBEVELINGS}

\section{Gesondheidsvoorligtingpraktyk}

Daar word aanbeveel dat die beramingsmodel van pasiënte deur studente gebruik en in die praktyk geïmplementeer word ten einde kultuurkongruente gesondheidsvoorligting te verseker en waardeverhelderingstrategieë toe te pas.

\section{Verpleegonderwys}

- Verpleegkundiges moet onderrig word ten opsigte van die verskillende kulture in Suid-Afrika se oortuiginge in verband met siekte en gesondheid, die invloed van kulturele waardes, die verskeie leefstyle asook die voorkoms van siektepatrone onder verskillende kulturele en etniese groepe.

- Daar moet 'n handleiding oor die verskillende kultuurgroepe in Suid-Afrika beskikbaar gestel word aangesien daar min boeke beskikbaar is oor die multikulturele konteks in verpleegkunde, wat in die verpleegkunde kurrikulum ingesluit word.

- Verpleegkundiges moet bekend raak met tale van ander kulture of ten minste sekere gebruikswoorde byvoorbeeld Chrisman se vraelys in die taal van die oorwegende etniese groep in die gemeenskap aanleer om sodoende kommunikasie hindernisse te oorbrug.

- Waardeverhelderingstrategieë moet 'n belangrike komponent van die studieprogram word en in elke module ingewerk word, sodat verpleegkundiges na voltooiing van elke module hulle eie waardes uitklaar en sodoende as sorggewers 'n oop en akkommoderende houding inneem.

\section{Navorsing}

Daar word aanbeveel dat die voorgestelde riglyne in die praktyk geïmplementeer word en dat die hele verloop van die studie na ' $n$ periode van ten minste twee jaar herhaal word om te bepaal tot watter mate die gesondheidsvoorligting wat deur verpleegkundiges aangebied word, kultuurkongruent is.

\section{BIBLIOGRAFIE}

ANON 1998: Journal of Scholarship: Image. Ethical standards for Nurse Researchers. Pretoria: Denosa, Maart 1998, pp. 1-7.

ANDREWS, MM \& BOYLE, JS 1995: Transcultural Concepts in Nursing Care. JB Philadelphia: Lippincott Company.

BROWNLEE, AT 1978: Community, Culture, and 
Care. A cross-cultural guide for health workers. St Louis: Mosby.

BURNS, N \& GROVE, SK 1987: The Practice of Nursing Research. Philadelphia: WB Saunders.

CHRISMAN, NJ 1991: Culture-Sensitive Nursing Care. (In: Patrick; Woods; Craven; Rokosky and Vruno eds. 1991: Medical-Surgical Nursing: Pathophysiologic Concepts; 2nd edition. Philadelphia: Lippincott.)

CHRISMAN, NJ 1991: Cultural Systems. (In: Susan Baird; Ruth McCorkie \& Marcia Grant eds. 1991: Cancer Nursing: A Comprehensive Textbook. Philadelphia: WB Saunders Co.)

CRESWELL, JW 1994: Research Design. Qualitative \& Quantitative Approaches. London: Sage publications.

DENZIN, NK \& LINCOLN, YS 1994: Handbook of Qualitative Research. United States of America: Sage Publication, Inc.

DINES, A \& CRIBB, A 1993: Health Promotion concepts and practice. Oxford: Blackwell Scientific Publications.

EDELMAN, CL \& MANDLE, CL 1990: Health promotion throughout the lifespan. St Louis: CV Mosby.

GIGER, JN \& DAVIDHIZAR RE 1991: Transcultural Nursing. Assessment and Intervention. St Louis: Mosby.

GROSS EJ 1994: "n Radikale strategie vir gesondheidsvoorligting. Johannesburg: Randse Afrikaanse Universiteit (D.Cur-proefskrif).

HEACOCK, P; SOUDER, E \& CHASTAIN, J 1996: Subjects, Data and Videotapes, Nursing Research, 45(6), Nov/Dec. 1996:336-338.

KOZIER, B; ERB, G \& BLAIS, K 1997: Professional Nursing Practice, Concepts and Perspectives. Menlo Park: Addison-Wesley.

KOZIER, B; ERB, G; BLAIS, K \& WILKINSON, JM 1998: Professional Nursing Practice, Concepts and Perspectives. Menlo Park: Addison-Wesley.

LEININGER, M 1978: Transcultural Nursing: Concepts, Theories and Practices. New York: A Wiley Medical Publication.

LEININGER, M 1995: Transcultural Nursing Concepts, Theories, Research \& Practices. New York: Greyden Press.
LEININGER, M 1996: Major Directions for Transcultural Nursing: A Journey into the 21 st Century. Journal of Transcultural Nursing, 7(2) Jan. - June 1996:28-31.

LEININGER, M 1997: Classic Article, Overview of the Theory of Culture care with the Ethnonursing Research Method. Journal of Transcultural Nursing, 8(2) Jan. - June 1997:32-51.

LINCOLN, YS \& GUBA, EG 1985: Naturalistic inquiry. Beverly Hills: Sage Publications.

MOUTON, J \& MARAIS, HC 1992: Basiese Begrippe: Metodologie van die geesteswetenskappe. Pretoria: Penrose.

RANDSE AFRIKAANSE UNIVERSITEIT 1992: Departement Verpleegkunde. Verplegingsteorie vir Mensheelheid. Johannesburg: Randse Afrikaanse Universiteit.

ROBERTS, BL; SROUR, MI \& WINKELMAN, C 1996: Videotaping: An important Research Strategy, Nursing Research, 45(6), Nov/Dec. 1996:334-338.

SUID-AFRIKAANSE RAAD OP VERPLEGING 1984: Goewermentskennisgewing R2598 van November 1984, soos gewysig. Regulasie betreffende die bestek van praktyk van persone wat kragtens die Wet op Verpleging, 1978 geregistreer of ingeskryf is. Pretoria: Staatsdrukker.

UYS, HHM \& BASSON, AA 1991: Navorsingsmetodologie in die Verpleegkunde. Pretoria: HAUM.

WOODS, NF \& CATANZARO, M 1988: Theory \& Practice. St Louis: Mosby.

WORLD HEALTH ORGANISATION: HEALTH AND WELFARE CANADA \& CANADIAN PUBLIC HEALTH SOCIETY 1986: Ottawa Charter for Health Promotion. An International Conference on Health Promotion, Ottawa, Ontario, Canada. 